\title{
LA TEORIA BRASILEÑA DEL HABEAS CORPUS PARA LOS GRANDES PRIMATES
}

Heron José de Santana Gordilho

Post-doctor (Pace University Law School, New York), Doctor Cum Laude (Universidade Federal de Pernambuco). Profesor Asociado (Universidade Federal de Bahia). Presidente de la Asociación Latinoamericana de Derecho Animal (ALDA). Fiscal del Medio Ambiente en Bahia, Brasil.

\section{Resumem}

El presente artículo analiza los fundamentos en la teoría brasileña del Habeas Corpus para los grandes primates, que funcionó como un precedente jurídico inédito, admitiendo a un chimpancé hembra en la condición de sujeto en un Habeas Corpus. A partir de una comparación entre la evolución humana y la evolución jurídica del artículo demuestra que, tal como las especies, el derecho también sufrió evolución para adaptarse a los cambios sociales, especialmente las recientes descubiertas científicas de la semejanza genética entre el hombre y los grandes primates. En esa línea, reclama la extensión de los derechos humanos para incluir entre los titulares chimpancés, bonobos, gorilas y orangotangos. La teoría establece, así, un nuevo sentido jurídico para el instituto del Habeas Corpus, hasta entonces utilizado para asegurar la libertad humana, para incrementar el movimiento social que reivindica los derechos de los animales y aumentar el grado de concienciación de la comunidad jurídica y de la población en general, sobre una de las cuestiones éticas más importantes de La época.

\section{Palavras-clave}

Evolución jurídica; Personalidad jurídica; Liberdad animal; Precedente judicial.

\section{Abstract}

This essay presents a comparison between human evolution and legal developments, trying to demonstrate how darwinian theory of evolution by natural selection has caused changes in the legal world, the bridge of today some lawyers using the recent discoveries about how similar genetic between man and great primates to claim extension of human rights for chimpanzees, bonobos, gorillas and orangs. It also that many activists for animal's rights have considered the dispute an important strategy, whether to set new means 
for legal institutes such as the Habeas Corpus, hitherto used only to ensure human freedom, whether to increase the movement and increase the conscietization of the general population about the importance of the recognition of animals as holders of basic rights.

\section{Key words}

Legal evolution; Legal personality; Animal freedom; Legal precedent.

\section{Introducción}

O evolucionismo applicado ao direito vae, entretanto, soffrendo o surto dessas collisões, antes da ver seu imperio completamente consolidado em toda a latitude da sciencia juridica.

Algumas rajadas mais fortes agitam-lhe hoje as construções. É preciso que examinemos a solidez da nau que nos conduz, que reconhecçamos se ella poderá vencer a violência dos vagalhôes e da ventania que esfusia-lhe hostil pelas cordagens.

\section{Clovis Bevilaqua ${ }^{1}$}

Toda idea responde a un patrón de cambio en el tejido moral de la sociedad, y no cabe duda que el lugar de los animales ha sufrido un desplazamiento de la periferia para el centro del debate ético, y el simple hecho de la expresión "derechos de los animales" haber convertido en vocabulario jurídico ya es un síntoma de dicho cambio.

Se constata una tendencia mundial de superación del antropocentrismo clásico, una vez que los elementos naturales, cada vez más, son objeto de consideración moral, ${ }^{2}$ muchas veces protegidos en detrimento de los intereses humanos inmediatos.

El pedestal en que nos ponemos gloriosamente comienza a presentar una serie de ranuras, y ya parece estar relegada a una pieza de museo, teniendo en cuenta que las características que pensábamos exclusivas de la humanidad, tales como la razón, el lenguaje, la cultura, la conciencia de si mismo, etc. han sido comprobadamente encontradas en otras especies, particularmente entre los grandes primates.

Por otro lado, ha ocurrido un aumento significativo de la conciencia social sobre los animales, y existe un mismo consenso según el cual ellos poseen intereses que deben ser

1 BEVILAQUA, Clóvis.. A Fórmula da Evolução Jurídica. In: Revista Acadêmica da Faculdade de Direito do Recife. Ano III. 1893. p.3.

2 LEITE, José Rubens Morato; AYALA, Patrick de Araújo. A transdisciplinariedade do direito ambiental e a sua eqüidade intergeracional. Revista de Direito Ambiental. São Paulo, Revista dos Tribunais, n. 22, abr./jun. 2001. p. 3. 
protegidos jurídicamente, aunque la mayoría de las personas todavía creen absurda la idea de concederles derechos. ${ }^{3}$

Ante la elasticidad de los textos legales, que en la mayoría de las veces son vagos y ambiguos, la operación hermenéutica opera con una inmensa libertad, de modo que la historia de la norma siempre adapta sus fuentes a las nuevas circunstancias, descubriendo en ellas las posibilidades inéditas que se alejan de lo que está ultrapasado y caduco. ${ }^{4}$

Los animales de compañía, por ejemplo, todavía son tratados en la esfera judicial como propiedad privada, lo que refuerza el concepto tradicional de derecho subjetivo cuńado en los siglos XVII y XVIII, ${ }^{5}$ que protege los intereses humanos, a pesar de superficiales, en detrimento de los intereses de los animales.

La teoría del Habeas Corpus para los grandes primates reivindica una interpretación analógica de los hechos, que aún hoy es considerada una importante fuente de derecho, una vez que el principio básico de justicia exige igual tratamiento para los casos semejantes, y una decisión judicial puede ser considerada arbitraria si tratar de un caso de una forma y otro caso semejante de forma distinta, sin que exista motivo relevante para ello. ${ }^{6}$

La interpretación analógica consiste en la utilización de una norma establecida para una determinada conducta para regular otra, desde que no sea posible identificar la norma aplicable para aquel caso, siempre que exista semejanza entre los supuestos facticos o jurídicos. ${ }^{7}$

Este artículo pretende inicialmente ofrecer al lector un análisis panorámico de la teoría darwiniana de la evolución de las especies, para en seguida describir los fundamentos del proyecto Grandes Primates, liderado por los profesores Peter Singer y Paola Cavaliere, que a partir del parentesco genético del hombre con chimpancés, bonobos, gorilas y orangotangos, defensa la inclusión de eses homínidos en nuestra esfera de consideración moral y jurídica.

3 BARTLETT, Steve J. Roots of human resistance to animal rights: psychological and conceptual blocks. Animal Law. Oregon. 2002, p. 146.

4 BOURDIEU, Pierre. O poder simbólico. Lisboa: Difel, 1989. p. 223.

5 PAYNE, Ruth. Animal welfare, animal rights, and the path to social movement's struggle for coherency in the quest for change. Virginia Journal of Social Policy and the Law Association. p. 620, Spring, 2002.

6 RACHELS, James. Do animals have a right to liberty. In:REGAN, Tom; SINGER, Peter. Animal rights and human obrigations. New Jersey: Prentice-Hall, 1976. p.206.

7 Según BOBBIO, Norberto, en ese tipo de interpretación el objetivo es la redefinición de un tiempo, aunque la norma aplicada sigue siendo la misma, presentando una nueva en el genero previsto en la ley en, Teoria do ordenamento jurídico, 10. ed., Brasília, UNB, 1999. p.156. En el mismo sentido FERRAZ JR., Tércio Sampaio, para quien la doctrina afirma que la interpretación extensiva pretende incluir el contenido de la norma en un sentido que ya estaba, solamente no había sido explicitado por el legislador en, Introduçáo ao estudo do direito: técnica, decisão, dominação, São Paulo, Atlas, 1990, p. 270. 
Después, será realizada un análisis de la teoría brasileña del Habeas Corpus para los grandes primates, a partir del estudio del caso Suiça vs Zoológico de Salvador, cuyo juzgado es considerado un precedente judicial histórico en favor de los grandes primates.

\section{Darwin y la Evolución Humana}

O naturalista não pode comparar nem classificar as faculdades mentais, mas apenas tentar demonstrar, como eu tenho feito, que entre as faculdades mentais do homem e dos animais inferiores não existe uma diferença essencial e específica, mas apenas uma imensa diferença de grau. Uma diferença de grau, por maior que seja, não nos autoriza a colocar o homem em um reino distinto.

Charles Darwin ${ }^{8}$

Hace más de 150 años, el naturalista inglés Charles Darwin publicaba "El origen de las especies" por la selección natural, libro que al desvelar el secreto de la evolución de la vida en nuestro planeta provocó una revolución científica tan importante, que quizás solo encuentre precedente en De la Revolución de las obras celestes, del astrónomo polaco Nicolau Copérnico, que estableció las bases del heliocentrismo moderno.

Publicada en 1858, esta obra aún hoy es consideradas una de las más influentes de todos los tiempos, y una de sus principales contribuciones fue refutar la teoría aristotélica de la inmutabilidad o rigidez del universo, hasta entonces concebido como un ente inmutable y jerarquizado, con cada especie ocupando un lugar apropiado, necesario y permanente.

Doce años después, en 1870, Darwin publica "El origen del hombre" seguido de "La expresión de las en el animal y en el hombre" (1872), donde demostraba por pruebas empíricas contundentes que entre el hombre y los animales las diferencias anatómicas y mentales son solamente de grado y no de esencia.

De hecho, la mayoría de los extraordinarios avances científicos de los últimos tiempos, de la ingeniería genética hasta la inteligencia artificial, no habían sido posible sin el conocimiento proveniente de la teoría de la evolución por la selección natural.

En 1836, después de su viaje a Beagle, donde pudo colectar datos como el registro fósil de los animales extintos, que parecían confirmar la idea de su abuelo, Erasmus Darwin y del pensador francés Lamark, según la cual las especies no son fijas y sufrían mutaciones con el paso del tiempo, Darwin hizo otro viaje científico a las islas de Galápagos,

8 DARWIN, Charles. El origen del hombre y la selección em relación al sexo. Madrid: Biblioteca E.D.A.F., 1989. p. 147. 
donde percibió que la separación geográfica tenía relación con la variación de las características entre las varias especies de pinzones y el poder modificador del medio ambiente.

En la oportunidad, Darwin percibió que algunas especies poseían un pico largo y afilado que servían para picar aves marinas y beber su sangre, al paso que otras poseían pico grueso y corto para romper semillas. Otras, a pesar de tener pico fuerte que servían para tumbar rocas y en la búsqueda de alimentos, detrás, por su parte, poseían pico estrecho y con una curvatura para comer mosquitos que vivían en cactos.

Además, él percibió que los extraordinarios cambios provocados en los animales de compañía a través de la reproducción controlada por cruzamientos sucesivos ( bulldog y el spaniel, por ejemplo), habían de ser aún más acentuadas entre las especies silvestres, una vez que en la naturaleza la acción selectiva dispone de un tiempo incomparablemente más largo.

Dos ideas están en el centro de la teoría: la primera es que la evolución deriva de un fenómeno histórico donde todas las especies descienden de un ancestral común; y la segunda, que la selección natural es el principal mecanismo de la biodiversidad.

Según Rebeca Stefoff, en otoño de 1836, al leer "Ensayo sobre la población de Tomas Malthus", que estudia las causas de la miseria humana y concluye que la vida es una lucha constante por la supervivencia donde muchos fallecen antes de atingir la vida adulta, Darwin va inferir que el principio de la selección natural demuestra, a partir de pruebas empíricas, que pequeńas variaciones en una especie son cruciales para determinar cuáles son los individuos que van a supervivir y dejar descendientes que heredaran sus características y cuáles van a perecer sin dejar descendientes.

Darwin probó que pequeñas diferencias aleatorias transmisibles entre los individuos de la misma especie (enajénese) determinan diferentes oportunidades de supervivencia y reproducción, permitiendo que algunos individuos sean bien sucedidos y otros no, y es este proceso, que ha determinado la especiación que provoca mutaciones en la forma, tamańo, fuerza, mecanismos de defensa, color, bioquímica y comportamiento de las futuras generaciones.

Como esas mutaciones genéticas ocurren solamente en un segmento aislado de cada especie, ellas permiten que solamente los individuos más a adaptados a las condiciones locales puedan ocupar un nuevo nicho ecológico. Con el paso del tiempo, esos individuos se tornan irreversiblemente diferentes, a punto de sus miembros no lograren más se reproducir como el de la antigua especie.

Dicho fenómeno de división de la especiación, Darwin denominó de "principio de la divergencia”, la idea que le permitió concebir la biodiversidad como un fenómeno de adaptación de las especies al medio ambiente. 
Cinco fueron las disciplinas determinantes en la colecta de las pruebas de la teoría de la evolución de Darwin: a) la biogeografía o el estudio de la distribución de los seres vivos; b) la paleontología, que investiga las formas de vida extintas preservadas en registros fósiles; c) la embriología, que analiza las etapas de desarrollo de los embriones; y, d) la morfología, que estudia la forma y la configuración anatómica de los seres vivos.

En 1839, después del nacimiento de su primero hijo con Emma Darwin, Wiliam Erasmus, Darwin pasó a observar el niño y comparar sus expresiones faciales con las de Jenny, una hembra orangután del zoológico de Londres, y pudo percibir la enorme semejanza entre las expresiones faciales y emociones de las personas y las de los grandes primates.

Después de la publicación de "El origen de las especies", un grupo de biólogos, entre ellos Thomas Huxley, uno de sus principales discípulos, examinó chimpancés y gorilas traídos por explotadores de las selvas africanas, y concluyeron que ellos eran más semejantes a los seres humanos que a los orangutanes.

Así, en 1863, Huxley publicó Man's place in nature, donde sugiere que existe una continuidad entre el cerebro de los grandes primates y de los hombres. Según él, en determinado momento del proceso evolutivo algunas especies comenzaron a seleccionar individuos que poseían un nuevo atributo adaptado - un cerebro aventajado - que poco a poco va le permitir desarrollar sofisticadas actividades mentales.

Solamente en 1872, al publicar "El origen del hombre y la selección en relación al sexo", Darwin va presentar su argumento sobre la evolución de la especie humana, cuando entonces sugiere que nuestra especie había evolucionado a partir de ancestrales semejantes a los grandes primates.

Aunque muchos tengan considerado, a la época, esas ideas absurdas, con el tiempo ellas fueron confirmadas por un conjunto de evidencias empíricas. Investigaciones desarrolladas por importantes universidades alrededor del mundo confirman el postulado darwiniano de que no existen diferencias categóricas entre el hombre y los animales no humanos, especialmente cuando se trata de analizar sus atributos mentales o espirituales.

Diversas de esas investigaciones demuestran claramente que el hombre es más una especie de la cadena evolucionaria, no existiendo ninguna característica que justifique las barreras existentes entre él y los animales no-humanos. Hoy es sabido, por ejemplo, que el propio desarrollo del cerebro humano no ocurrió para aislarlo de las leyes de la supervivencia de la reproducción, sino para cumplirlas con mayor eficacia.

Según estudios recientes humanos y primates se dividieron en especies diferentes hace más o menos 5 millones de años, una parte ha evolucionado para los actuales chimpancés y bonobos y la otra para la formación de primates bípedes erectos que han evolucionado para especies como el Homo Australopithecus, el Homo Ardipithecus y el Homo 
Paranthropu, a pesar de que ancestro común de la especia humana con los chimpancés y gorilas son mucho más reciente de lo que el ancestro común de los chimpancés y gorilas con los primates asiáticos, por ejemplo, como el gibones y orangutanes. Esta proximidad evolutiva representa semejanzas importantes entre esas especies y el hombre.

Jane Goodall, por ejemplo, convivió durante treinta y uno años con un grupo de chimpancés en el Parque Nacional de Gombe, en Tanzania, y probó que esos animales poseen individualidades y relaciones sociales bien complejas, y que además del parentesco genético, son dotados de una estructura cerebral y un sistema nervioso central extraordinariamente semejante a los nuestros.

Las sociedades de los primates, por ejemplo, son basadas en la cooperación, división social del trabajo, estrategias de manipulación, punición y reconciliación. Además de eso, gorilas, chimpancés, bonobos y orangutanes, así como los humanos, poseen mismo una inteligencia capaz de resolver problemas sociales, atributo ese que les facilita la supervivencia y la reproducción.

En regla, se reúnen en familia o clanes compuestos de jóvenes y ancianos, machos y hembras, que se dividen en diversos grados de parentesco y subgrupos, semejantes a los nuestros partidos políticos o asociaciones de barrios.

En 1753, 106 años antes de Origen de las Especies, Cark von Lineu había publicado la obra Species Plantarum, sistematizando el orden natural de las especies, afirmando que las especies eran invariables, reforzando la equivocada dicotomía entre el poderoso hombre, aislado en el alto, y los humildes primates, próximos de la bestialidad.

Desde el fin del siglo XIX, sin embargo, con el surgimiento de la biología como una disciplina fundada en la teoría de la evolución, el sistema de la clasificación ven procurando reflexionar sobre la historia de la evolución de las especies, aunque todavía sea hecho de una forma circular y subjetiva, primero decidiendo los parentescos, y solamente después buscando evidencias anatómicas que compraban esas presunciones.

En la segunda mitad del siglo XX surgió un nuevo modelo taxonómico, denominado cladístico, que pasó a clasificar los animales en base a la similitud anatómica, en la distancia genética y en el tiempo de separación entre las especies.

Willi Hennig, considerado el fundador de la cladística (del griego Klados = ramo), desarrolla la teoría sistemática filogenética donde defensa que los organismos deben ser clasificados de acuerdo con sus relaciones evolutivas, a partir del análisis de los caracteres ancestrales y derivados de cada especie.

Diferentemente de la taxonomía tradicional, en ese momento las inferencias sobre la historia evolucionaria antes de la clasificación, y no después, y con el adviento de la sistemática molecular, que utiliza el analice del genoma y los métodos de la biología molecular, hemos asistido a profundas revisiones de la clasificación de las especies. 
De hecho, un grupos de científicos, utilizando la moderna tecnología de analice genético, recientemente publicó en la prestigiosa revista americana Proceedings of the National Academy of Sciences, una investigación que revela que las semejanzas entre los códigos genéticos del hombre y del chimpancé son casi idénticos, siendo posible afirmar que esas especies pertenecen a la misma familia (hominidae) y al mismo genero (Homo)

Además de las características anatómicas fundamentales, como el pecho liso, un particular camino de los dientes molares, la ausencia de la cola, etc., el análisis genético reveló que no hace mucho tiempo los grandes primates tuvieron un ancestro común con los hombres.

El Smithsonian Institute, por ejemplo, ya adopta ese esquema de clasificación, y en las últimas ediciones de la publicación Mammals Species of the World, los miembros de la familia de los grandes primates integran la familia de los hominideos, que pasan a ser clasificados como Homo troglodytes (chimpancés), Homo paniscus (bonobos) e Homo sapiens (hombres) e Homo gorilla (gorilas).

Hoy sabemos que los grandes primates poseen atributos mentales muy semejantes a los de la especie humana, y que la exclusión de ellos de nuestra comunidad de iguales es moralmente injustificable, arbitraria e irracional, una vez que en términos biológicos, no pode haber ninguna categoría natural que incluya los chimpancés, gorilas y orangutanes y excluya la especie humana.

Como hemos visto, Darwin probó que no existe ninguna diferencia ontológica entre la especie humana y los animales, lo que nos lleva a concluir que nada justifica la exclusión de ellos de nuestra esfera de consideración moral, incluso porque, así como nosotros, esas criaturas poseen los intereses fundamentales por la vida, libertad e integridad física y psíquica.

No obstante, a pesar del enorme prestigio de Darwin en el mundo científico, los juristas todavía siguen operando con institutos que se chocan frontalmente con los postulados evolucionistas. Para el mundo jurídico es como se Darwin nunca hubiera existido.

\section{Evolución Jurídica y Derecho de los Animales}

Considerando que o ativismo dos direitos dos animais cada vez mais envolve o direito, um estudo desse movimento deverá se mostrar informativo. Assim como outros movimentos sociais, o movimento pelos direitos dos animais aumentou sua confiança no sistema judicial.

Helena Silverstein?

9 SILVERSTEIN, Helena. Unleashing rights: law, meaning, and the Animal Rights Movement. Michigan: University of Michigan. 1996, p.17. 
Así como las ideas, la jurisprudencia también cambia, y cuando la opinión publica toma partido para determinado lado, difícilmente el judiciario se opone a ella, a ejemplo de la esclavitud brasileña, que ya estaba en plena decadencia en el momento en que el movimiento abolicionista obtuvo la final victoria. En la época de la abolición de la esclavitud muchos esclavos huyeron de las fincas y no temían la recaptura, puesto que la opinión pública apoyaba dicha situación.

Cambios en la cultura jurídica, con todo, dicen respecto tanto con el nivel de profesional de los operadores jurídicos (jueces, fiscales, abogados, legisladores), como con el proceso de formación académica de eses profesionales, especialmente en lo que se refiere al enfoque filosófico predominante en las universidades. ${ }^{10}$

Los juristas, en general, todavía son escépticos en relación a la posibilidad de la admisión de los animales en juicio como titulares de derechos, y ante la ausencia de un soporte legislativo claro, los tribunales muchas veces evitan la toma de una decisión avanzada.

Muchos creen que mismo que exista un soporte efectivo efectiva de la opinión publica $^{11}$ una decisión de ese tipo sería insignificante, reformista e ineficaz, puesto que difícilmente habría una fuerza política capaz de ejecutarla. ${ }^{12}$

Otros consideran la retorica abolicionista contraproducente, una vez que ella estigmatiza la mayoría de las personas que, de una forma o de otra, participan del sistema de explotación institucionalizada de los animales, y eso solo contribuye para elevar la resistencia psicológica a ese tipo de cambio.

No obstante, a pesar de eses inconvenientes, entendemos que el judiciario puede ser un poderoso agente en el proceso de cambio social, una vez que no solamente detiene el poder, sino el deber de actuar cuando el legislativo se recusa hacerlo. Muchas veces el es el único capaz de corregir las injusticias sociales cuando los demás poderes son comprometidos políticamente o se encuentran atados a los intereses de grandes grupos económicos. ${ }^{13}$

10 LOPES, José Reinaldo de Lima. Direito e transformaçáo social: ensaio interdisciplinar das mudanças no direito. Belo Horizonte:Nova Alvorada, 1997, p.108.

11 PAYNE, Ruth. Animal welfare, animal rights, and the path to social movement's struggle for coherency in the quest for change. Virginia Journal of Social Policy and the Law Association. p. 619, Spring, 2002.

12 Para HAMILTON, Alexander et al, $\mathbf{O}$ federalista: um comentário à Constituição americana, Rio de Janeiro, Nacional de Direito, 1959, p. 312, "O judicial, em troca, não influi nem sobre as armas, nem sobre o tesouro; não dirige a riqueza nem a força da sociedade, e não pode tomar resoluçáo ativa. Pode se dizer realmente, que não possui FORÇA nem VONTADE, senão unicamente discernimento, e que tem de se apoiar definitivamente na ajuda do braço executivo até mesmo para que tenham eficácia suas sentenças". Por otro lado, según PAYNE, Ruth, op. cit. 2002, p. 600: "Rosenberg afirma que apesar dos tribunais estarem impedidos pela Constituição de promover reformas sociais, quando as condiçōes políticas, sociais e econômicas se tornam favoráveis a mudança, eles podem efetivamente prover significativas mudanças sociais" (Traducción nuestra)..

13 PAYNE, Ruth. Animal welfare, animal rights, and the path to social movement's struggle for coherency in the quest for change. Virginia Journal of Social Policy and the Law Association. p. 600, Spring, 2002. 
Algunos autores creen que es necesario enfrentar la cuestión de los derechos de los animales no-humanos a partir de la necesidad de expandir el rol de los sujetos de derecho, otorgándoles personalidad jurídica.

Henrry Salt, ya en el siglo XIX, afirmaba que si los hombres poseen derechos, los animales también los poseen, desde que se entienda por derechos "un sentido de justicia que marque las fronteras donde el consentimiento acaba y la resistencia empieza; una demanda pela libertad de vivir la propia vida y la necesidad de respectar la igualdad de libertad de los demás". ${ }^{14}$

Es que cuando utilizamos la palabra "derecho", hacemos con una carga valorativa positiva, vía de regla para representar una situación jurídica en la perspectiva de aquellos que se encuentran en posición favorable en relación a otro o a alguna cosa. ${ }^{15}$

Pese el enorme prejuicio enfrentado por los animales no-humanos en el mundo jurídico, es preciso recordar que el derecho es poblado de sujetos no-humanos como empresas, municipios, Estados, iglesias, etc.

Según Laurence Tribe, los argumentos utilizados para negar reconocimiento de los derechos animales no-humanos no pasan de mitos, puesto que hace mucho tiempo el derecho desarrolló el instituto de la persona jurídica para admitir que seres inanimados puedan pasar a ser sujetos de derecho. ${ }^{16}$

Si examinamos la historia del Derecho, percibimos que ni todos los hombres son (o fueron) considerados persona, de la misma forma ni todas las personas son seres humanos. ${ }^{17}$

Los juristas de la Edad Media, por ejemplo, pasaron mucho tiempo debatiendo sobre la posibilidad de se conceder personalidad jurídica para "organismos corporativos", como la iglesia y el Estado. ${ }^{18}$

14 SALT, Henry. Animal's rights: considered in relation to social progress. Pensylvannia: Society for Animals Rights, 1980. p. 2.

15 FERRAZ JÚNIOR, Tércio Sampaio. Introdução ao estudo do direito: técnica, decisão, dominação. Săo Paulo: Atlas, 1990. p.144.

16 De acuerdo con TRIBE, Laurence "Ten Lessons our Constitutional Experience can Teach us About the Puzzle of Animal Rights: The Work of Steven M. Wise." In: Animal Law Review. 2001. p.3: "Ampliar o círculo dos sujeitos de direito, ou mesmo ampliar a definiçáo de pessoa, eu admito, é é amplamente uma questão de aculturação. Não é uma questáo de quebrar alguma coisa, como uma conceitual barreira do som."

17 FRANCIONE, Gary. "Personhood, Property and Legal Competence". In: The Great Ape Project:equality beyond humanity. CAVALIERI, Paola and SINGER, Peter (ed) New York: St. Martin. 1993, p.252. Segundo RABENHORST, Eduardo. Dignidade Humana e Moralidade Democrática. Brasília: Brasília Jurídica, 2001, p.68:"Sujeito de direito não é o homem entendido como ser biológico, mas qualquer ente susceptível de contrair direitos e obrigaçōes.",

18 Segundo STONE, Christopher. Should tree have standing?: Haw far will law and moral reach? a pluralist perspective. Southern California Law Review. Southern California, 1985, p.3 : "Como estas corporaçôes poderiam existir legalmente, como entidades transcendentes à existência do Papa e do Rei? 
Mismo la expresión "ser humano" suele ser utilizada en sentidos que ni siempre se armonizan, puesto que en un primer momento ella se refiere al conjunto de los integrantes de la especie Homo sapiens, en otros momentos ella exige "indicadores de humanidad", tales como la conciencia de sí, autocontrol, noción de pasado y futuro, capacidad de relacionarse, preocuparse, comunicarse con los demás y curiosidad. ${ }^{19}$

Efectivamente, la palabra "persona” fue introducida en el discurso filosófico por el estoico Epictetus, que la utilizó para describir el papel que cada individuo representaba en la vida social. ${ }^{20}$ En la Roma Antigua, por ejemplo, solamente el individuo que reunía determinados atributos, como el nacimiento con vida, forma humana, viabilidad fetal y perfección orgánica suficiente para continuar a vivir; además del status de ciudadano libre y capaz, podría ser considerado persona, ${ }^{21}$ al paso que mujeres, niños, esclavos, extranjeros y los propios animales eran considerados res. ${ }^{22}$

El proceso de identificación del concepto de persona con el de ser humano solo apareció en el pensamiento occidental a partir del cristianismo, que luchó contra la distinción romana entre ciudadanos y esclavos. ${ }^{23}$

De hecho, el fundamento moral del cristianismo tiene como punto de partida la sacralización de la vida humana, una vez que todos los hombres estarían destinados a una vida común después de la muerte del cuerpo. ${ }^{24}$

Para contractualistas como John Locke, el concepto de persona está vinculado a las ideas de razón y conciencia de sí, de modo que la persona es todo ser inteligente y pensante, dotado de razón, reflexión y capaz de considerar a sí mismo como una misma cosa pensante en diferentes tiempos y lugares. ${ }^{25}$

Para Kant, la "persona” representa todo el ser racional y auto-consiente, capaz actuar de manera distinta de un mero espectador, tomando decisiones y ejecutándolas con la consciencia de perseguir intereses propios. $^{26}$

Estava claro que um Rei podia se auto-obrigar - para sua honra - através de um tratado. Mas quando o Rei morresse, o que seria feito das cláusulas, reivindicadas como direito - que suas tangíveis máos tinham assinado? ”. (Traducción nuestra).

19 SINGER, Peter . Ética Prática. trad. Jefferson Luís Camargo. São Paulo: Martins Fontes, 1998. p. 96.

20 HALL, Lee and WATERS, Jon. From Property to person: The case of Evelyn Hart. Disponíbel en http:/ www. Personhood.org/lawreview. Capturado em 8 de maio de 2006.p.9.

21 Segundo CRETElla Jr., José. Curso de Direito Romano. Rio de Janeiro: Forense. 1999. p. 252: “pessoa é noção eminentemente jurídica, que não se confunde com homem.”.

22 Idem. Ibidem p.252.

23 FERRAZ JR, Tércio Sampaio. Introdução ao Estudo do Direito: Técnica, Decisão, Dominação. São Paulo: Atlas, 1990. p.148.

24 SINGER, Peter. Libertaçáo Animal. trad. Marly Winckler. Lugano. 2004. p.217.

25 LOCKE, John. An Essay Concerning Human Understanding, London: George Routledge and Sons Limited. p.246.

26 KANT, Emanuel. Doutrina do Direito. trad. Edson Bini. São Paulo: Ícone, 1993. p.37: "Uma pessoa é o sujeito cujas ações são suscetíveis de imputação. De onde se conclui que uma pessoa pode ser submetida tâo-somente às leis que ela mesma se dá (seja a ela sozinha, seja a ela ao mesmo tempo que a outros).” 
Lo que sucede es que dicho concepto, estructurado a partir de los conceptos de razón y consciencia en si han sido superados teóricamente, ya que su mantenimiento llevaría al absurdo de excluir de nuestra esfera de consideración moral los recién-nacidos y los portadores de enfermedades mentales.

Los recientes avances de la medicina y de las ciencias biomédicas han puesto de manifiesto varias cuestiones éticas sobre la personalidad jurídica, una vez que existen seres humanos que no podrían, en sentido estricto del término, ser considerados persona, como aquellos acomedidos de muerte cerebral, pero mantenidos vivos por aparatos que destinan sus órganos para donación o el embrión concebido por violación, que puede ser abortado dentro de ciertas condiciones.

Por otro lado, muchas investigaciones presentan pruebas empíricas de que los delfines, orcas, elefantes y animales como los perros y cerdos son seres inteligentes, racionales y dotados de consciencia de sí, lo que les habilitaría a ser considerados personas. ${ }^{27}$

No nos olvidemos que le Código Civil de 2006 excluyó una de las principales barrera erguidas por los civilistas para afirmar que el derecho es hecho exclusivamente para la especie humana, y sus dos primeros artículos, al tratar de la personalidad y la capacidad, sustituyo la palabra hombre que se encontraba en el antiguo código por la palabra persona, ${ }^{28}$ demostrando claramente que persona natural y ser humano son conceptos independientes.

Steve Wise, que defensa la inmediata extensión de los derechos subjetivos a los chimpancés y bonobos (chimpancés pigmeos), argumentando que esos animales poseen una capacidad mental que les permitiría ser aprobados en testes que normalmente son aplicados en los seres humanos, utiliza la teoría de los derechos subjetivos de Wesley Hohfeld para defensa que los grandes primates poseen derechos individuales negativos o privilegios, tales como la libertad corporal y la integridad física. ${ }^{29}$

Para él, si los jueces conceden derechos de dignidad para los niños y personas con graves enfermedades mentales a partir de la ficción legal de que "todas las personas son autónomas", por las mismas razones deberían reconocer que los grandes primates poseen esos derechos. ${ }^{30}$

27 SINGER, Peter. "Prefácio". In:YNTERIAN, Pedro A. Nossos Irmãos Esquecidos. São Paulo: Arujá, SP: Terra Brasilis, 2004, p.4.

28 Según AGUIAR, Mônica. Direito à Filiaçáo e Bioética. Rio de Janeiro:Forense. 2005, p.33: "Essa mudança, realizada no Senado Federal sob a batuta do senador Josaphat Marinho, foi por ele justificada como necessária a afastar o estigma de sexismo na utilização da expressão homem, como genérica para indicar todo ser humano, seja do sexo feminino ou masculino."

29 WISE, Steven. Rattling the cage: toward legal rights for animals. Cambridge and Massachussett: Perseus . 2000. p. 61.

30 Ibid. p. 255 . 
En Brasil, la cuestión se torna aún más delicada, puesto que la Constitución de 1988 elevó la prohibición de las prácticas que sometan los animales a crueldad a la categoría de derecho fundamental, lo que le confirió aplicabilidad inmediata, ${ }^{31}$ a pesar de su constante violación. ${ }^{32}$

\section{La Teoría Brasileña del Habeas Corpus en Favor de los Grandes Primates}

Acredito que mesmo com a morte de Suica (chimpanzé) o problema continuará a ser discutido, especialmente nas salas das faculdades de direito, visto que muitos colegas, advogados, estudantes e entidades têm manifestado as suas opinióes, e pretendem fazer com que prevaleçam. O assunto não vai morrer com esse habeas corpus, isto certamente terá controverso.

Steven Wise ${ }^{33}$

En enero de 2005, yo ya había retornado a mis actividades en la $2^{\text {a }}$ Fiscalía del Medio Ambiente, en Salvador, en el Estado de Bahia. Yo había concluido los créditos y estaba escribiendo mi tesis sobre los derechos de los animales para el doctorado del Programa de Pos Grado de la Facultad Federal de Pernambuco.

Yo había acabado de leer la obra "The great ape project" de Peter Singer y Paola Cavalieri, y me ha parecido muy interesante la afirmación que hicieron destacando que los grandes primates constituyen el punto débil del chauvinismo humano, y que deberíamos concentrar nuestros esfuerzos en ese punto. ${ }^{34}$

Todos sabemos que Singer no reivindica el reconocimiento de derechos para los animales, él simplemente defensa la inclusión de los grandes primates en el género humano, permitiendo así que ellos sean alcanzados por los derechos humanos.

31 BRASIL. Constituição (1988). Art. $5^{\circ} \$ 1^{\circ}$. As normas definidoras de direitos e garantias fundamentais têm aplicação imediata.

32 Según BENJAMIN, Antonio H. Constitucionalização do ambiente e a ecologizaçấo da Constituição brasileira. In: CANOTILHO, José Joaquim e LEITE, José Rubem Morato (Orgs). Direito constitucional ambiental brasileiro. São Paulo: Saraiva. 2007, p. 99: "A falta de zelo dos beneficiários na sua fiscalização e defesa não afeta sua validade e eficácia, pois são verdadeiramente direitos atemporais, vacinados contra os efeitos jurídicos decorrentes, como regra, da inaçáo das vítimas diante da prepotência dos degradadores."

33 WISE,Steven. The entitlement of chimpanzees to the common law writs of Habeas Corpus and the Homine Replegiando. In: Golden Gate University Law Review. Vol. 37, 2006-2007, p.219.

34 Para CAVALIERI, Paola; SINGER, Peter. The great ape project: equality beyod humanity. New York: St. Martin’s Press. 1993, p.386: “ Para aqueles que aspiram a mudança, é de vital importância que compreendam o marco no qual devem atuar, e que aproveitem as contradiçóes existentes nas posturas dos oponentes.... Os reformadores apenas podem partir de uma situaçáo dada e trabalhar a partir dela. Uma vez que há conseguido alguns avanços, seu ponto de partida seguinte estará um pouco adiante, e quando conseguirem ter força suficiente, podem exercer pressão a partir desse ponto." (Traducción nuestra). 
Cierto día llegando a mi despacho tuve una idea que cambiaría completamente mi vida: si los grandes primates pueden ser sujetos de derechos humanos ellos pueden ser pacientes en un Habeas Corpus para la defensa de su libertad física.

Yo vivía cerca del Zoológico de Salvador y como mis hijos estaban en la primera infancia, yo ya conocía los dos chimpancés que ahí estaban enjaulados.

Me enteré que uno de ellos, "Geron”, había fallecido, en 20 de abril de 2005, instauré, ex oficio, un procedimiento de n. 8/2005 para apurar las condiciones de vida de los chimpancés en aquel establecimiento.

En seguida, intimé los veterinarios del zoológico para una audiencia, momento en el cual me han confirmado que "Geron" había muerto de cáncer, en el día 19 de marzo de 2005, y que su compañera "Suiça” vivía en una jaula de 73 metros cuadrados. A partir de aquel momento yo tomé una decisión: presentaría un Habeas Corpus a favor de aquella chimpancé.

Aunque ya tenía en mis manos los fundamentos teóricos para el hecho, sabia que no podría tomar aquella aptitud sin el apoyo de otras personas. Yo sabía que sería insultado y ridiculizado por personas que nunca pararon para pensar en la condición en que vivían los animales.

Después de más de cinco meses entre la apertura del procedimiento hasta la presentación del Habeas Corpus, en 19 de septiembre de 2005, y de la contribución de varias personas en el hecho, especialmente el fiscal Luciano Rocha Santana y el entonces asesor administrativo de la fiscalía: Tagore Trajano.

La verdad es que yo nunca había interpuesto un Habeas Corpus en mi vida profesional. Muy raramente los fiscales lo hacen. Todo lo que yo tenía era un texto confuso formado por la captura de mi tesis doctoral. Después de idas y venidas, varios borradores descartados, llegamos al texto final del Habeas Corpus.

A partir de entones, investimos en encontrar personas dispuestas a donar apoyo político al recto, mismo porque la noticia ya circulaba por los pasillos de la Universidad Federal de Bahia y Universidad Católica de Salvador, y hasta en la Fiscalía del Estado de Bahia.

Más de un mes después obtuvimos el apoyo de las personas que darían legitimidad al proceso. Algunos de los profesores llegaron a firmar el Writ y después se arrepintieron, argumentando haber sufrido mucha presión por parte de sus pares.

Otros, sin embargo, dieron inmediato apoyo político a nuestra acción, y a mí me gustaría darles las gracias: los profesores Samuel Vida, Georgeocohama Archanjo, Antonio Ferreira Leal Filho y José Amando Mascarenhas Júnior, las activistas Gislane Brandão (Asociación “Bicho Feliz"), Edna Teixeira (Asociación “Brasileira de Defesa dos Animais”) y Ana Rita Tavares (Asociación "Brasileira Terra Verde Viva”), y a los estudiantes Thiago 
Pires, Otto de Jesus, Ana Paula Carvalho, Ana Thais Dummond, Fernanda Oliveira, Arivaldo Souza y Sara Barbosa.

En 19 de septiembre de 2005, finalmente dimos entrada en el Writ que recibió el no 833085-3/2005, y contrariando a las expectativas más conservadoras, en el día siguiente el Juez Edmundo Lúcio da Cruz, titular de la $9^{\text {a }}$ Vara Criminal del Tribunal de Justicia del Estado Estado de Bahia, reconociendo "tratar-se de materia compleja, que exige alta indagación y profundo examen", denegó el pedido de liminar y recibiendo la demanda determinó la intimación de la autoridad coautora para informaciones, abriendo un precedente histórico para el mundo jurídico.

Uno de los principales argumentos presentados en el Writ fue la interpretación evolutiva, que objetivaba encontrar la voluntad autónoma de las normas para adecuarlas a la realidad social, en razón de cambios históricos, sociales o políticos, atribuyéndoles nuevos contenidos. ${ }^{35}$

Con el paso del tempo, la hermenéutica jurídica, después de acumular una serie de experiencias, crea mecanismos de cambios y adaptación jurídica, desde los juicios de equidad a la interpretación analógicas, que terminan por posibilitar la convivencia de normas, que a pesar de contradictorias, continúan validas. ${ }^{36}$

Muchas veces los valores sociales tornan una norma obsoleta, como a título de ejemplo, el articulo 219, IV, del antiguo Código civil brasileño, que autorizaba la anulación del matrimonio por error de persona siempre que la mujer hubiera sido desvirgada y ese caso fuera ignorado por el marido, artigo que mismo antes del actual Código Civil ya había sido revocado por la costumbre negativa. ${ }^{37}$

De hecho, podemos encontrar, a lo largo de la historia, actos judiciales que operaron verdaderos efectos de cambios no-formal, mediante adaptaciones efectuadas por procesos de interpretación de la Constitución. ${ }^{38}$

Uno de los ejemplos clásicos de dichos cambios no-formales pasó durante la vigencia de la Constitución de 1891, con la denominada doctrina brasileña del Habeas Corpus, desarrollada a partir de las ideas de Rui Barbosa, que extendió a la utilización de aquel instituto del derecho criminal a los conflictos civilistas dónde se identificaba una amenaza de derecho o imposibilidad de su ejercicio por ilegalidad del abuso del poder. ${ }^{39}$

35 BARROSO, Luis Roberto. Interpretação e aplicação da constituição. 6. ed. São Paulo: Saraiva, 2004. p. 146.

36 LOPES, José Reinaldo de Lima. Direito e transformaçáo social: ensaio interdisciplinar das mudanças no direito. Belo Horizonte: Nova Alvorada, 1997. p. 94-95.

37 BRASIL. Código Civil (1917). Art. 218, caput, e 219, VI

38 BRITO, Edvaldo, Limites da Revisão Constitucional. Porto Alegre:Sérgio Antonio Fabris. 1993, p.85.

39 BARROSO, Luís Roberto. O direito constitucional e a efetividade de suas normas. 7. ed. Rio de Janeiro: Renovar, 2003. p.180. Segundo SIDOU, J. M. Othon. Habeas corpus, mandado de segurança, 
Es importante subrayar que aunque ese tipo de litigio no alcanzara los objetivos esperados, puede servir de modelo y repercutir positivamente en la esfera social, a ejemplo de lo que pasó en Brasil en 1880, cuando el abolicionista Luiz Gama ingresó con un Habeas Corps a favor del esclavo Caetano Congo, que había sido preso en Sao Paulo por huir de una finca del Municipio de Campinas, donde constantemente sufría malos tratos.

En ese Habeas Corpus, Luis Gama argumentó que el paciente naciera en la costa de África, y, aunque hubiera sido registrado hace cincuenta ańos, su verdadera edad era 58, puesto que en aquella época los contrabandistas no importaban niños menores de 10 años. Así, logró demonstrar que Caetano había sido trasladado a Brasil en 1832, o sea, un año después que la ley había consignado como ilegal el comercio transatlántico de esclavos. ${ }^{40}$

Aunque la justicia haya recusado el Writ y Caetano Congo haya sido devuelto a su propietario, el hecho repercutió negativamente contra los esclavistas, lo que contribuyó políticamente para el fomento del movimiento abolicionista. ${ }^{41}$

En el derecho constitucional Norteamericano vamos encontrar otro ejemplo clásico de la evolución jurídica. Como la Constitución estadunidense de 1787, en sección 2 del artículo 1, autorizaba la esclavitud, en 1857, el famoso caso Dred Scott vs Sandford, la Suprema Corte negó a un esclavo la condición de ciudadano. ${ }^{42}$

La abolición de la esclavitud en 1865, por la $13^{a}$ enmienda, treinta y uno ańos después (1896) esta misma Corte juzgó el caso Plessy vs Ferguson, afirmando que la doctrina de los iguales, pero separados (equal but separate), impidiendo el acceso de estudiantes negros a las escuelas frecuentadas por blancos.

Solamente en 1954, ochenta y nueve años después de la abolición, en el juzgado del caso Brown vs Board of Education, la Suprema Corte americana va declarar inconstitucional la segregación de estudiantes negros en las escuelas públicas. ${ }^{43}$

En relación a los animales, en 1972, esa misma Suprema Corte de los Estados Unidos juzgó el famoso caso Sierra Club vs Morton, a partir de una demanda presentada

mandado de injunçáo, habeas data, açáo popular:as garantias ativas dos direitos coletivos, 5. ed., Rio de Janeiro, Forense, 1998, p. 126-127:"A teoria era simplíssima, autêntico ovo de Colombo, à mais singela observação do texto constitucional. Que garante o Habeas Corpus? A resposta universal é: a liberdade de locomoção. Qual o pressuposto objetivo, letra constitucional à vista do remédio heróico? A violência ou coação ilegal. E qual o seu pressuposto subjetivo? A ilegalidade ou o abuso de poder, ou seja, a afronta a qualquer princípio constitucionalmente consagrado. Desde pois que essa afronta se cometa em forma de privação da liberdade de locomoção, caso é de Habeas Corpus.

40 MENDONÇA, Joseli M. N. Entre a mão e os anéis: a lei dos sexagenários e os caminhos da abolição no Brasil. Campinas: Unicamp, 1999. p. 173.

41 Ibid.

42 BARROSO, Luis Roberto. Interpretaçáo e aplicação da constituição. 6. ed. São Paulo: Saraiva, 2004, p. 68 .

43 Ibid. 
por la Asociación Sierra Club contra la US Forest Service solicitando la anulación de la licencia administrativa que autorizaba la construcción de una estación para deportes de invierno en el Mineral King Valley, ubicado en la sierra Californiana y bastante conocida por abrigar varias especies de sequoias. ${ }^{44}$

Como el Tribunal de Apelación de California había rechazado el pedido, por considerar que ningún miembro de la asociación había sufrido perjuicio, el profesor Christopher Stone escribió un ensayo seminal con el titulo Should trees have standing? Toward legal rights for natural objects, que fue adjuntado al proceso ya en la fase de ser juzgado por la Suprema Corte. ${ }^{45}$

En ese artículo, Stone desarrolla el argumento de la continuidad histórica del derecho, que va ampliando cada vez más en su esfera de protección, de los niños a las mujeres, de los esclavos hasta las sociedades comerciales, asociaciones y colectividades públicas, para concluir que no había razón para refutar la titularidad de los derechos a los animales y a las plantas, que estarían en aquella demanda por la Asociación Sierra Club. ${ }^{46}$

No obstante, contrariando todas las expectativas, tres de los siete jueces de la $\mathrm{Su}$ prema Corte de los EUA se declararon favorables a los argumentos de presentados por Stone, y aunque la tese haya sido derrotada, el voto del juez Marshall se tornó antológico, al afirmar que si en aquel país los navíos y las corporaciones podrían ser titulares de derechos, no existirían razones para negar la extensión de eses derechos a los animales y a las plantas. ${ }^{47}$

Como en el Habeas Corpus es el paciente sujeto de derecho en el caso Suiça vs Zoológico de Salvador el juez tubo que, inicialmente, admitir que si el Writ cumplía las condiciones de la demanda, y para ello tuvo que entrar a analizar se Suiça tenía o no legitimidad ad causam, eso es, si podría o no ser titular de derecho de libertad de locomoción, si el pedido era posible y si el paciente tenía interés de actuar.

Es que en nuestro sistema, antes de decir si recibe o no una petición inicial, el juez procede a una cognición provisional de mérito, analizando los elementos constantes en la citación de la otra parte cuando está convencido, si et in quantum, de la veracidad de las

44 OST, François. A natureza à margem da lei: a ecologia à prova do direito. Lisboa: Instituto Piaget, 1995. p.199. En el derecho procesal civil norte-americano el derecho de acción exige que el autor demuestre (1) la existencia de un dańo efectivo; líquido y cierto, actual o inminente; (2) el vinculo de causalidad entre ese dańo y la conducta indicada; y (3) que el dańo alegado pueda ser reparado o compensado por remedio judicial adoptado en, KELCH, Thomas G. Toward a non-property status for animals. New York University Environmental Law Journal, New York, p. 535, 1998.

45 FERRY, Luc. A nova ordem ecológica: a árvore, o animal, o homem. São Paulo: Ensaio, 1994. p. 15.

46 Ibidem. p. 16.

47 OST, François. A natureza à margem da lei: a ecologia à prova do direito. Lisboa: Instituto Piaget, 1995. p. 202. 
alegaciones del autor y de la probable procedencia del pedido, mismo porque esa decisión no en un simple impulso del proceso, sino una decisión liminar de contenido positivo y de naturaleza interlocutoria. ${ }^{48}$

Además, fue necesario analizar los presupuesto procesales del hecho, decidiendo si su juicio era competente para juzgarlo y si los impetrantes tenían capacidad procesal y postuladora para ingresar con el Writ.

Al hacer ese juicio preliminar de admisibilidad de la acción, el juez debe, a partir de entonces considerar inepta la petición inicial y extinguir el proceso sin entrar en el mérito. ${ }^{49}$

Por desgracia, en el día 27 de septiembre de 2005, la chimpancé Suiça falleció, y el proceso fue extinto sin entrar en el mérito, teniendo la muerte del paciente conducido al desaparecimiento del objeto, que consistiera en la coacción ilegal de su libertad de locomoción. ${ }^{50}$

En la sentencia final, publicada coincidentemente en el día 4 de octubre de 2005 el propio juez admite que podría haber extinguido el hecho, ab initio litis, juzgando inepta la pieza inicial, por imposibilidad jurídica del pedido y falta de interés de actuar delante de una pretensión inadecuación del instrumento procesal. Pero no lo hizo, y quedará en la historia como el primero juez brasileño a reconocer un grande primate como sujeto de derecho.

El juez Edmundo citó un antiguo precedente del Supremo Tribunal Federal (STF), más actualizado con su tiempo asevera:

Tenho a certeza que, com a aceitação do debate, consegui despertar a atenção de juristas de todo o país, tornando o tema motivo de amplas discussões, mesmo porque é sabido que o Direito Processual Penal não é estático, e sim sujeito a constantes mutaçôes, onde novas decisôes têm que se adaptar aos tempos hodiernos. ${ }^{51}$

48 MOREIRA, José Carlos Barbosa. Novo processo civil brasileiro. 20. ed. Rio de Janeiro: Forense, 2000, p. 23.

49 DIDIER JÚNIOR, Fredie. Pressupostos processuais e condiçóes da açáo: o juízo de admissibilidade do processo. São Paulo: Saraiva, 2005. p. 302.

50 CÂMARA, Alexandre Freitas. Liçóes de direito processual civil. Rio de Janeiro: Lumen Juris, 2002. p. 204.

51 BRASIL. Habeas Corpus n. 833085-3/2005 da 9a Vara Crime da Cidade do Salvador, Bahia. Juiz Edmundo Lúcio da Cruz. Diário do Poder Judiciário, 4 de outubro de 2005. Na sentença, o Juiz afirma "É certo que, com tal decisão inicial, admitindo o debate em relação ao assunto aqui tratado, contrariei alguns 'juristas de plantáo', que se esqueceram de uma máxima do direito romano que assim preceitua: Interpretatio in quacumque dispositione sic facienda ut verba non sint superflua et sine virtute operandi (em qualquer disposiçáo deve-se fazer a interpretaçáo de modo que as palavras náo sejam supérfluas e sem virtude de operar)". 
Es importante destacar, que el proceso, a pesar de interrumpido, no puede ser considerado inválido, mismo porque, en la fundamentación de la sentencia el juez dejó claro que el Writ cumplía todas las condiciones de la acción, es decir, que la tutela jurisdiccional postulada era sucesible de apreciación, que las partes eran legítimas y que la vía procesal del Habeas Corpus era un instrumento necesario y adecuado y, por lo tanto, podría llegar a un resultado satisfactorio para la paciente.

Así, el caso Suiça vs Zoológico de Salvador representó un precedente judicial histórico, un marco judicial del derecho brasileño, al hacer valer una de las principales reivindicaciones del movimiento por los derechos de los animales: el reconocimiento de los animales como sujetos de derecho, dotado de capacidad de reivindicar eses derechos en juicio.

Es necesario subrayar que aunque Suiça no hubiera fallecido y el juez no admitiera el Writ, considerando, por ejemplo, que el santuario para el cual se pretendía trasladar Suiça no ofrecía mejores condiciones que la jaula del zoológico de Salvador, el hecho ya había sido tornado inédito, puesto que lo importante en ese juzgado fue el reconocimiento de que un animal no humano puede ser sujeto de derecho.

El hecho obtuvo repercusión positiva, tanto en la prensa como entre los activistas y científicos de varias universidades del mundo, los cuales celebraron el hecho, enviando mensajes de solidaridad a los autores de la demanda y al magistrado. ${ }^{52}$

De ese modo, el caso Suiça vs Zoológico de Salvador demostró que así como las especies, las ideas también avanzan, y que el mundo jurídico no puede simplemente dar las espaldas para los nuevos conocimientos científicos.

Después de la decisión del juez Edmundo Cruz, el hecho que ya había llamado la atención de la prensa nacional, pasó a ser objeto en la prensa internacional. Así, periódicos como La Voz de Galicia (España), Angola Press (Angola), Zanimljivosti (Hungría), Nachrichte (Alemania), Turnul Babel (Romania) pasaron a noticiar el caso.

Los debates ocurrieron en todos los lugares, aunque la sociedad estuviera dividida, el caso contribuyó con el aumento de la consciencia de las personas para la cuestión de la explotación institucionalizada de los animales.

52 Según SILVA, Tagore Trajano de A. Brazilian Animal Law Overview: balancing human and non human interests. In: Journal of Animal Law. Vol. VI, Michigan State University. 2010, p.91: Como dicho anteriormente, la principal cuestión en el caso Suiça vs Zoológico de Salvador es saber se el Habeas Corpus es el instrumento adecuado para la protección de la libertad de los animales. Sea como fuera, ese caso objetivó extender los derechos humanos, tales como los derechos de libertad, vida y integridad física, a los grandes primates, teniendo en vista la semejanza genética entre ellos y los seres humanos. La discusión tuvo repercusión nacional e internacional, por debates en periódicos y televisión alrededor del mundo. (Traducción nuestra). 
Mientras muchos ridiculizaban la iniciativa, centenas de activistas, sociedades protectores y científicos de varias partes del mundo enviaron mensajes de apoyo al Fiscal General del Estado de Bahia. Con el apoyo de mis amigos, resistí a todos los ataques y todavía hoy existen personas que son reacias a la discusión del tema.

Mismo entre los autores que reivindican los derechos de los animales como Carlos Neconency $^{53}$, Daniel Lourenco ${ }^{54}$ y Gary Francione ${ }^{55}$ la teoría ha sido objeto de críticas, puesto que dichos autores entienden que el argumento de la proximidad genética, por si solo, no debe justificar la inclusión de los grandes primates en la categoría de "persona", utilizando el argumento del riesgo de caer en un "especismo selectivo", que dejaría de fuera las demás especies.

No obstante, de la misma forma que aquellos que se oponen a los derechos de los animales, es un equivoco descalificar la teoría del Habeas Corpus para los grandes primates, atacando lo que es justamente el punto más sólido de su construcción: demonstrar que las premisas del antropocentrismo son falsas, abriendo camino para la revolución científica, permitiendo la inclusión de otros animales no-humanos en el mundo jurídico.

Además de eso, el hecho de que los grandes primates sean considerados como "persona" no impide que otras especies también puedan ser reconocidas como sujeto de derecho, sea como ente jurídico despersonalizados o defesados por una demanda llamada acción civil pública.

No tengo ninguna duda que el caso Suiça, por haber sido un marco en los casos de los precedentes que contribuyó a la repercusión pública que obtuvo, representó un avanzo jurídico importante, que seguramente servirá de modelo para otras contribuciones.

\section{Conclusiones}

Acredito que mesmo com a morte de Suica (chimpanzé) o problema continuará a ser discutido, especialmente nas salas das faculdades de direito, visto que muitos colegas, advogados, estudantes e entidades têm manifestado as suas opiniōes, e pretendem fazer com que prevaleçam. $\mathrm{O}$ assunto não vai morrer com esse habeas corpus, isto certamente continuará controverso.

Steven Wise ${ }^{56}$

53 NACONECY, Carlos Michelon. Ética \& Animais: um guia de argumentação filosófica. Porto Alegre: EDIPUCRS, 2006.

54 LOURENÇO, Daniel Braga. Direitos dos animais: fundamentação e novas perspectivas. Porto Alegre: Sergio Antonio Fabris.2008, p.490 e ss.

55 FRANCIONE, Gary. The Great Ape Project: not so great. Disponible en: <htpp:/www.garyfrancione. blobspot.com>. Acceso en 9 de Septiembre de 2011.

56 WISE,Steven. The entitlement of chimpanzees to the common law writs of Habeas Corpus and the Homine Replegiando. In: Golden Gate University Law Review. Vol. 37, 2006-2007, p.219. 
Como vimos, la teoría brasileńa del Habeas Corpus para los grandes primates utiliza los avances científicos que compraban que los grandes primates son especies que integran el mismo género de la humanidad para reivindicar la inclusión de esas criaturas en la comunidad jurídica.

El avance de la genética permitió el descubrimiento de que esas criaturas no forman un género en separado de la especie humana, sino al contrario, ellos integran el mismo género de la humanidad, y eso no solo es fruto de una interpretación jurídica avanzada, sino también un hecho científicamente comprobado.

Es importante destacar que los grandes primates no pertenecen a la fauna brasileña, son animales que viven en África y en Asia, pero ante el deslumbre que provocan, están encarcelados en varios países alrededor del mundo, en colecciones particulares, zoológicos y circos, hay una estimativa de que la población total de los grandes primates sea menor que el total del número diario de nacimientos de la especie. ${ }^{57}$

Mismo partiendo del paradigma antropocéntrico, es imperativo admitir que es injustificable la exclusión de esas criaturas de nuestra consideración moral y de la esfera judicial estatal.

Así como la extensión de los derechos de los grandes primates no significa un descaso en relación a los humanos, ella también no significa una omisión en relación a las demás especies, incluso, al revés, abriendo las puertas para un cambio jurídico hacia una abolición de la explotación institucionalidad de los animales.

En una democracia el derecho puede ser un importante instrumento de cambio social, y el caso de Suiça demostró que además de las teorías, la judicialización de los debates en la área de los derechos de los animales puede contribuir para el cambio social.

Algunos ańos se pasaron, las cosa están cambiando para mejor: el mundo académico ya discute la temática, investigando y produciendo trabajos jurídicos, y hasta los operadores del Derecho empiezan a familiarizaren con el problema jurídico.

El precedente judicial extraído de ese caso tuvo por lo menos tres consecuencias positivas a favor de los derechos de los animales: a) amplió el debate público de la cuestión; b) estimuló el movimiento social a favor de los derechos de los animales; y c) incluyó la cuestión del mundo jurídico brasileño de una forma nunca antes imaginada.

Nosotros sabemos que el derecho cambia, pero también que el suele coger el último tren de la historia. Es que los operadores, muchos de ellos integrantes de la cúpula del Poder del Estado, están fuertemente sometidos a las fuerzas económicas y a los factores de poder.

57 Population Action International (PAI). Relative Scarcity:Apes on the Edge.Disponível em http://www. actionbioscience.org/biodiversity/pai.html. Capturado em 15.11.2011. 
No obstante, algunas veces, el mundo jurídico puede salir delante de la sociedad para a partir de decisiones judiciales que, al principio contrarían el sentido común, acaban por ampliar el espectro a la dignidad humana.

\section{Referencias}

AGUIAR, Mônica. Direito à Filiaçáo e Bioética. Rio de Janeiro:Forense. 2005.

BARROSO, Luís Roberto. O direito constitucional e a efetividade de suas normas. 7. ed. Rio de Janeiro: Renovar, 2003.

BARROSO, Luis Roberto. Interpretação e aplicação da constituição. 6. ed. São Paulo: Saraiva, 2004.

BARTLETT, Steve J. Roots of human resistance to animal rights: psychological and conceptual blocks. Animal Law. Oregon. 2002.

BENJAMIN, Antonio H. Constitucionalização do ambiente e a ecologização da Constituição brasileira. In: CANOTILHO, José Joaquim e LEITE, José Rubem Morato (Orgs).Direito constitucional ambiental brasileiro. São Paulo: Saraiva. 2007.

BOBBIO, Norberto. Teoria do ordenamento jurídico, 10. a Ed. Brasília:UNB.1999.

BOURDIEU, Pierre. O poder simbólico. Lisboa: Difel, 1989.

BRITO, Edvaldo, Limites da revisáo constitucional. Porto Alegre: Sérgio Antonio Fabris. 1993.

BURGIERMAN, Denis Russo. Chimpanzés são humanos. Superinteressante. São Paulo, Abril,, julho, 2003.

CÂMARA, Alexandre Freitas. Liçóes de direito processual civil. Rio de Janeiro: Lumen Juris, 2002.

CAPRA, Fritjof. As conexóes ocultas: ciência para uma vida sustentável. São Paulo: Cultrix, 2002.

CARVALHO, André e WAIZBORT, Ricardo. A mente darwiniana, Em, Viver mente \& cérebro, fev., 2006.

CAVALIERI, Paola; SINGER, Peterr. The great ape project: equality beyod humanity. New York: St. Martin's Press. 1993.

CRETELLA JR, José. Curso de Direito Romano. Rio de Janeiro: Forense, 1999.

DAWKINS, Richard. DAWKINS, Richard. "Gaps in the Mind”, In: CAVALIERI, Paola and

DIDIER JÚNIOR, Fredie. Pressupostos processuais e condiçóes da açáo: o juízo de admissibilidade do processo. São Paulo: Saraiva, 2005. 
DIAMOND, Jared. The third chimpanzee. In: The great ape project: equality beyond humanity. New York:St. Martin., p. 88-101, 1993.

DUNBAR, R. I. M. What's in a classification. The great ape project: equality beyond humanity. New York. 1993, p.109-112.

FERRY, Luc. A nova ordem ecológica: a árvore, o animal, o homem. São Paulo: Ensaio, 1994.

FRANCIONE, Gary. "Personhood, Property and Legal Competence". In: The Great Ape Project:equality beyond humanity. CAVALIERI, Paola and SINGER, Peter (ed) New York: St. Martin. 1993.

GOODMAN, Morri set al. Implicatios of natural selection in shaping 99.4\% nonsynonymous DNA identity between humans and chimpanzees: enlarging genus homo. Detroit: Wayne State University School of Medicine. 2003. Disponível em <htpp:// www.intl.pnas.org>. Acesso em 9 ago 2007.

GORDILHO, Heron J. S. Abolicionismo animal. Salvador:Evolução.2009.

HALL, Lee and WATERS, Jon. From Property to person: The case of Evelyn Hart. Disponíbvel em http:/ www. Personhood.org/lawreview. Capturado em 8 de maio de 2006.

HAMILTON, Alexander et al, $\mathbf{O}$ federalista: um comentário à Constituição americana, Rio de Janeiro, Nacional de Direito, 1959.

KANT, Emanuel. Doutrina do Direito. trad. Edson Bini. São Paulo: Ícone, 1993.

LEITE, José Rubens Morato; AYALA, Patrick de Araújo. A transdisciplinariedade do direito ambiental e a sua eqüidade intergeracional. Revista de Direito Ambiental. São Paulo, Revista dos Tribunais, n. 22, abr./jun. 2001.

LOCKE, John. An Essay Concerning Human Understanding, London: George Routledge and Sons Limited. p.246.

LOPES, José Reinaldo de Lima. Direito e transformação social: ensaio interdisciplinar das mudanças no direito. Belo Horizonte: Nova Alvorada, 1997.

LOURENÇO, Daniel Braga. Direitos dos animais: fundamentação e novas perspectivas. Porto Alegre: Sergio Antonio Fabris.2008.

MENDONÇA, Joseli M. N. Entre a mão e os anéis: a lei dos sexagenários e os caminhos da abolição no Brasil. Campinas: Unicamp, 1999.

MOREIRA, José Carlos Barbosa. Novo processo civil brasileiro. 20. ed. Rio de Janeiro: Forense, 2000.

NACONECY, Carlos Michelon. Ética \& Animais: um guia de argumentação filosófica. Porto Alegre: EDIPUCRS, 2006. 
OST, François. A natureza à margem da lei: a ecologia à prova do direito. Lisboa: Instituto Piaget, 1995.

PAYNE, Ruth. Animal welfare, animal rights, and the path to social movement's struggle for coherency in the quest for change. Virginia Journal of Social Policy and the Law Association. Spring, 2002.

QUAMMEN, David. Darwin estava errado?. National Geografic Brasil. São Paulo, nov., 2004.

RABENHORST, Eduardo Ramalho. Dignidade humana e moralidade democrática. Brasília: Jurídica, 200.

RACHELS, James. Do animals have a right to liberty. In:REGAN, Tom; SINGER, Peter. Animal rights and human obrigations. New Jersey: Prentice-Hall, 1976.

RANGEL, Paulo. Direito processual penal. 5. ed. Rio de Janeiro: Lumen Juris, 2001.

SIDOU, J. M. Othon. Habeas corpus, mandado de segurança, mandado de injunçáo, habeas data, açáo popular:as garantias ativas dos direitos coletivos, 5. ed., Rio de Janeiro, Forense, 1998.

SILVA, Tagore Trajano de A. Brazilian Animal Law Overview: balancing human and non human interests. In: Journal of Animal Law. Vol. VI, Michigan State University. 2010.

SILVERSTEIN, Helena. Unleashing rights: law, meaning, and the Animal Rights Movement. Michigan: University of Michigan, 1996.

SINGER, Peter. "Prefácio”. In:YNTERIAN, Pedro A. Nossos Irmãos Esquecidos. São Paulo: Arujá, SP: Terra Brasilis, 2004.

Libertação Animal. trad. Marly Winckler. Salvador: Evolução. 2008.

STEFOFF, Rebecca. Charles Darwin: A revolução da evolução. São Paulo: Companhia das Letras. 2007.

SUNSTEIN, Cass R. The rights of animals. University of Chicago Review. Chicago, 2003.

TRIBE, Laurence. "Ten Lessons our Constitutional Experience can Teach us About the Puzzle of Animal Rights: The Work of Steven M. Wise.” In: Animal Law Review. 2001.

WISE, Steven M. Rattling the cage: toward legal rights for animals. Cambridge and Massachussett: Perseus. 2000.

WISE,Steven M. The entitlement of chimpanzees to the common law writs of Habeas Corpus and the Homine Replegiando. In: Golden Gate University Law Review. Vol. 37, 2006-2007, p.219-290. 